\title{
Spina bifida transition to adult healthcare guidelines
}

\author{
Ellen J. Fremion ${ }^{\mathrm{a}, \mathrm{b}, *}$ and Nienke P. Dosa ${ }^{\mathrm{c}}$ \\ ${ }^{a}$ Transition Medicine Clinic, Baylor College of Medicine, Houston, TX, USA

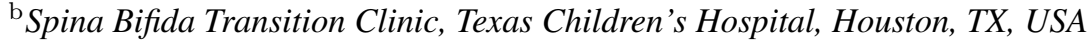 \\ ${ }^{\mathrm{C}}$ Center for Development Behavior and Genetics, SUNY Upstate Medical University, Syracuse, NY, USA
}

\begin{abstract}
With an estimated 85\% of individuals with spina bifida (SB) surviving into adulthood, SB-specific transition to adult healthcare guidelines are warranted to address the diverse and complex medical, adaptive, and social needs particular to this condition. This commentary discusses the SB Transition Healthcare Guidelines from the 2018 Spina Bifida Association's Fourth Edition of the Guidelines for the Care of People with Spina Bifida, reviews current transition care models in which such guidelines can be implemented, and explores further research topics in SB transition care.
\end{abstract}

Keywords: Spina bifida, transition to adult healthcare, adolescent medicine, developmental disability

\section{Introduction}

Spina Bifida (SB) is a complex condition that impacts multiple organ systems and is associated with varying degrees of lifelong physical, cognitive, and adaptive impairment [1-3]. The prevalence of open $\mathrm{SB}$ (myelomeningocele) is 3 in 10,000 births. With pediatric SB care advancements since the 1970s, an estimated $85 \%$ of individuals with SB survive well into adulthood necessitating attention to their particular transition to adult healthcare needs [4-6]. This article aims to (1) discuss the development of the Spina Bifida Association's Transition Guidelines, (2) evaluate SB transition care models, and (3) explore future SB transition research topics.

\section{Goals of transition}

Transition to adult healthcare is the "purposeful, planned movement of adolescents and young adults

${ }^{*}$ Corresponding author: Ellen Fremion, 7200 Cambridge St., Houston, TX 77030, USA. Tel.: +1 713798 6333; Fax: +1 713798 0198; E-mail: ellen.fremion@bcm.edu. with chronic physical and medical conditions from child- to adult-oriented healthcare" [7]. This process incorporates preparation, planning, and follow-up from early adolescence through young adulthood [8]. The goal of transition is to "maximize lifelong functioning and potential through the provision of high-quality, developmentally appropriate healthcare services that continue uninterrupted as the individual moves from adolescence to adulthood" [7].

\section{SB transition guidelines}

The SB Transition Healthcare Guidelines is a new section in the Fourth Edition of the Spina Bifida Association's Guidelines for the Care of People with Spina Bifida (Table 1) [9]. These guidelines are the result of three years of planning, literature review, and content development by experts in SB care including pediatric and adult physicians from multiple subspecialties, psychologists, and nurses. Given that transition to adult care is a growing field, there is limited evidence to support particular transition practices. Thus, the guidelines are primarily based on expert consensus with literature references as applicable (guidelines are summarized in 
Table 1

Spina bifida transition guideline summary by age group

\begin{abstract}
Throughout the lifespan 1. Provide the individual/family with a probable trajectory for adult function and expectations for optimal independence according to the individual's abilities.

2. Provide information for families regarding long-term financial, insurance, and supportive living planning based on the individual's abilities.

3. Provide information to the individual/family as to where they can access comprehensive care throughout the lifespan.

Ages 6-11 years

1. Consider neurocognitive assessment to identify cognitive, adaptive, or learning support needs if concerns are identified.

2. Evaluate chronic condition management, such bladder and bowel regimens, and adjust to facilitate selfmanagement and social independence.

Ages 12-17 1. Consider having a designated transition clinic or care coordinator to support transition planning and coordination.

2. Ensure that the patient's views and preferences are included in transition planning.

3. Review the clinic's transition policy with patients and families that summarizes the transition approach, transfer process, decision-making, and patient privacy.

4. Ensure patient-centered and developmentally appropriate preventative and chronic condition management services are provided throughout transition. Evaluate management plans and assess for necessary adaptive equipment and supplies to maximize independent function.

5. Consider neurocognitive assessment to identify cognitive, adaptive, or learning support needs if concerns are identified and have not previously been addressed.

6. Designate time alone with the adolescent for at least part of their visit, if developmentally appropriate.

7. Discuss the transition plan with adolescent and family routinely. The plan should include:
\end{abstract}

a. A medical summary including past medical and surgical history, current care plans, emergency care plans, medications, allergies, vaccines, and current providers.

b. Self-management skill assessment and invention based on the individual's skills and potential to improve. Consider using a validated transition and self-management assessment tools such as TRAQ and AMIS [35, 36].

c. Long-term financial, insurance, and supportive living (housing and transportation) plans based on the individual's current needs and probable trajectory of adult function.

d. Education and employment resources such as vocational rehabilitation services, school transition planning as part of the Individualized Educational Plan, and adaptive vocational accommodations.

e. Decision-making supports that maximize the individual's ability to participate in decisions at age 18 , such as a medical power of attorney, supportive decision-making, or guardianship. Referral for neurocognitive testing and to medical legal partnerships may be needed.

f. Information regarding the Social Security Administration's Disability Determination Services before age 18 , as applicable.

Age 18 and above $\quad$ 1. Ensure individuals establish care with appropriate adult providers including primary care and urology.

2. Continue to ensure patient-centered and developmentally appropriate preventative and chronic condition management. Evaluate management plans and assess for necessary adaptive equipment and supplies to maximize independent function.

3. Continue to provide counselling on long-term financial, insurance, and supportive living (housing and transportation) plans, based on the individual's current needs and probable trajectory.

Table 1). The following objectives governed the guideline development:

1. Maximize health and participation in emerging adult milestones throughout the transition process.

2. Provide patient-centered, comprehensive transition care that includes: transition planning and care coordination beginning by age 14; selfmanagement coaching; decision-making support; education and employment resources; and independent-living support.

3. Promote access to uninterrupted, developmentally appropriate SB condition management and preventative care throughout transition - specifically, ages 14-21.

\section{Transition planning throughout the lifespan, beginning in the prenatal and infancy periods}

Understanding the individual's probable adult functional trajectory guides lifelong transition planning. In general, individuals with higher lesions (i.e. above L2) and hydrocephalus require support for bowel and bladder management, mobility, self-care, transfers, and activities of daily living throughout life $[10,11]$. By age 30 , approximately one-third of individuals with SB 
are fully independent, one-third need occasional assistance, and one-third routinely need assistance for daily care needs [12]. Compared with their typicallydeveloping peers, individuals with SB may have a twoto five-year delay in developing autonomy skills [13]. Lifelong optimization of condition management, family function, socialization, school performance, mental health, and self-management support maximal adult health and quality of life attainment [11,12,14-17].

Successfully navigating funding resources promotes access to care. Private and public insurance eligibility and coverage vary amongst plans and age groups and are subject to change. From the 2009-2012 National SB Patient Registry (NSBPR) Data, 53\% of patients age 22 or younger lacked private insurance which was associated with decreased bowel/bladder continence and community ambulation [18]. Thus, individuals with Medicaid may need more supports to ensure access to needed services. State-based home and community based-service waivers offer funding for adaptive living needs. However, waiver services, eligibility, and wait-list time are unique to each state and subject to change. Therefore, SB providers should routinely review care needs, current coverage, and future coverage plans with all age groups and particularly during the transition years.

Finally, SB providers should aid individuals in accessing comprehensive care throughout the lifespan. The predominant SB pediatric model is for patients to be seen annually in a SB multidisciplinary clinic [19]. However, this clinic model is not typically found in adult healthcare systems. Partnerships between adult and pediatric providers, administration, payers, patients and families, and advocacy groups are needed to create sustainable, comprehensive SB care models throughout the lifespan.

\section{Transition planning ages $6-18$}

Regardless of lesion level, individuals with SB may have diminished or delayed self-management, independent living, and healthcare navigation skills [20]. For AYASB, self-management skills proficiency predicts decreased urinary tract infections, hospitalizations, and anxiety/depression and increased family satisfaction [21,22]. Physical or intellectual disability, lower socioeconomic status, lower family health literacy, and minority racial/ethnic background predict decreased health status, regimen adherence, and functional independence $[18,23,24]$. Children with SB who have better condition knowledge; self-efficacy; and participation in decision-making, problem-solving, self-care, and household responsibilities demonstrate higher levels of self-management and social competence [25-28]. Parental expectation and encouragement fosters independent skill development. Conversely, parental over-protection hinders developmental potential $[3,17,29]$. SB providers should routinely evaluate the individual's participation in self-management tasks and household chores and offer appropriate parental counseling, nurse education, and regimen adjustment to promote independence. Neurocognitive testing or physical/occupational therapy may aid in evaluating and improving self-care.

\section{Transition planning ages 12-18}

In addition to the on-going chronic care described above, pediatric clinics should review a clinic transition policy and care plan with patients and families beginning at age 12-14 [30]. The transition policy should explain the clinic's approach to preparing and transferring the adolescent from a pediatric to adult care [30]. Transition care plans should include transfer timing, who will assume care throughout transition, a medical summary, a transition readiness/self-management assessment and intervention, higher education and employment options, transportation/adaptive driving options, and decision-making support options. The recommended components for a SB-specific transition plan are reviewed below. The Got Transition Website (www.gottransition.org) provides examples of general transition policies, transition plans, and selfmanagement assessment tools [31]. The Spina Bifida Association website provides a SB-specific medical summary and information sheets (www.spinabifidaas sociation.org) [32].

\subsection{Medical summary}

Recommended medical summary components are medical and surgical history, current care plans, emergency care plans, medications, allergies, vaccines, current providers, cognitive/physical function, and selfmanagement assessment [33]. Condition care plans document the date of diagnosis, severity of condition and/or associated comorbidities, previous pertinent evaluations and interventions, provider (s) managing the condition, and the current management. Emergency plans list the signs and symptoms of condi- 
tion exacerbation as well as evaluation and treatment considerations. Shunt malfunction, urinary tract infections, and skin ulcers pose the greatest risk for adult hospitalization and thus should be included in emergency care plans [34]. Updating the medical summary with the patient/family during transition visits can guide patient education and organize care management.

\subsection{Assessment and intervention for transition readiness and self-management}

The Transition Readiness Assessment Questionnaire (TRAQ), measuring participation in general transition-age tasks, and the Adolescent/Young Adult SelfManagement and Independence Scale II (AMIS II), measuring independence both SB specific and general AYA self-management tasks, have been previously used with AYASB [35-37]. Goal-setting interventions show promise in improving care responsibility, independence, and general executive functioning for AYASB [38-40]. However, condition-related attention, memory, and executive function (planning, organizing, and completing tasks) impairments may necessitate more practice and coaching to accomplish goals $[41,42]$. Goal success depends on patient and family/caregiver engagement $[25,43]$.

\subsection{Education and employment}

AYASB have lower employment rates than their typically developing peers [44]. Higher executive function, socioeconomic status, parental support, and bowel continence predict adult employment. Thus, future school/work planning should integrate self-management independence and continence management [23]. Early preparation for higher education/work accommodations, financial, housing, transportation, and vocational rehabilitation yields successful school-work transition [15]. Transition providers should offer transportation, volunteering, and day program resources to individuals unable to work/attend higher education to maximize their community participation as well.

\subsection{Decision-making}

Decision-making ability at age 18 varies amongst AYASB. Discerning the individual's decision-making capacity around age 17 with the patient/family guides counseling on independent decision-making, supportive decision-making, and guardianship options. If able, adolescents should learn to provide their health information and meet with their doctor independently throughout transition to foster decision-making independence [30].

\section{Transition hand-off and integration into adult care ages $18+$}

Transfer to adult care typically occurs between ages 18-21 [45]. This process encompasses the exchange of medical records and care plan responsibilities as well as monitoring to ensure successful establishment with adult care [30]. Gaps in care access during transfer can lead to condition exacerbation and increased acute care [46]. Thus, transfer timing should be flexible to ensure that medical conditions are stable, care plans are current, and patients have continuous access to funding and providers prior to discharge from pediatric care.

\section{Models of care}

A 1994 study documenting suboptimal outcomes for AYASB after the disbanding of a multidisciplinary clinic sparked SB transition model research [47]. In 2008, the Maternal Child Health Bureau Division of Children with Special Health Care Needs summarized both SB-specific and non-specific approaches to SB transition [48]. A non-SB specific approach may be particularly suitable to combined internal medicinepediatrics programs that can offer complex transition care to bridge pediatric and adult services [49]. For example, the Riley Children's Hospital Center for Youth and Adults with Conditions of Childhood provides consultative visits for patients with chronic conditions during the transition years and the Baylor College of Medicine Transition Medicine Clinic provides a medical home for adults with intellectual and developmental disabilities transferring into adult care [50,51].

Over the past decade, SB condition-specific Transition Models have emerged coincidentally with NSBPR development. In such models, nurses and social workers provide SB-specific navigation support and self-management coaching to promote independence and successful transfer [52-54]. Currently, two NSBPR clinics offer lifelong care, however many pediatric clinics coordinate transfer to adult primary care in an affiliated institution. Several clinics offer joint visits with adult healthcare providers, e.g. the Lurie Children's Hospital SB Clinic affiliated with the Shirley 
Ryan AbilityLab and the Texas Children's SB Transition Clinic affiliated with the Baylor College of Medicine Transition Medicine Clinic [55,56]. Urology transition research has identified that AYASB often have active urologic concerns during transition and thus, urology-specific transition clinics have been proposed as well [57-60]. Interagency models linking SB pediatric clinics with community-based programs or camps for transition and self-management independence support have also been described [38,61].

A 2017 Spina Bifida Association survey assessing transition care in NSBPR clinics documented that transition concepts are generally discussed, but most clinics do not routinely evaluate their transition process and only $30 \%$ communicate with adult providers [62]. SB transition guideline implementation provides a cohesive strategy to improve the standardization of transition care and study transition outcomes.

\section{Areas of future research and conclusions}

Potential areas of future research for SB transition include (1) identifying barriers and facilitators of selfmanagement independence, health status, and engagement in secondary education/vocation for adults with SB that may inform transition counseling and intervention; (2) determining successful interventions to improve adult SB care access; and (3) determining best transition care models to promote health outcomes, quality of life, and transition readiness, and successful transfer. Consensus is also needed on AYASB health status, self-management, and care access outcome measures.

SB transition planning is a particularly challenging given the variability and complexity of the condition and differences between pediatric and adult healthcare systems for SB care. This article offers guidance on SB transition program content that SB providers, individuals and families, administration, payers, and advocates can collaboratively adapt to their local resources and population needs. Specific care management guidelines for AYASB can be found by topic and age group on the Guidelines for the Care of People with Spina Bifida website (https://www.spinabifidaassociation.org/ guidelines/).

\section{Conflict of interest}

The authors have no real or apparent conflicts of interest to disclose.

\section{References}

[1] Parker SE, Mai CT, Canfield MA, Rickard R, Wang Y, Meyer $\mathrm{RE}$, et al. Updated national birth prevalence estimates for selected birth defects in the united states, 2004-2006. Birth Defects Res Part A. 2010; 88: 1008-1016.

[2] Agopian AJ, Canfield MA, Olney RS, Lupo PJ, Ramadhani T, Mitchell LE, et al. Spina bifida subtypes and sub-phenotypes by maternal race/ethnicity in the national birth defects prevention study. Am J Med Genet Part A. 2012; 168A: 109-115.

[3] Loomis JW, Javornisky JG, Monahan JJ, Burke G, Lindsay A. Relations between family environment and adjustment outcomes in young adults with spina bifida. Developmental Medicine \& Child Neurology. 1997; 39: 620-627.

[4] Hunt GM, Oakeshott P. Outcome in people with open spina bifida at age 35: Prospective community based cohort study. BMJ. 2003; 326(7403): 1365-1366.

[5] Bowman RM, McLone DG, Grant JA, Tomita T, Ito JA. Spina bifida outcome: A 25-year prospective. Pediatr Neurosurg. 2001; 34: 114-120.

[6] Dillon CM, Davis BE, Duguay S, Seidel KD, Shurtleff DB. Longevity of patients born with myelomeningocele. Eur J Pediatr Surg. 2000; 10: 33-34.

[7] American Academy of Pediatrics, American Academy of Family Physicians AC of P-AS of IM. Consensus statement on health care transitions for young adults. Pediatrics. 2002; 110(Supplement 3): 1304-1306.

[8] Cooley WC, Sagerman PJ. Supporting the health care transition from adolescence to adulthood in the medical home. Pediatrics. 2011; 128(1): 182-200.

[9] Brei T, Stuwe S, Beierwaltes P, Dicianno B, Dosa N, Raman L, et al., editors. Guidelines for the Care of People wiht Spina Bifida An Initiative of the Spina Bifida Association [Internet]. Fourth Edi. Arlington, VA: Spina Bifida Association. 2018. Available from: https://www.spinabifidaassociation.org/app/ uploads/Guidelines-for-the-Care-of-People-with-SpinaBifida-2018.pdf

[10] Verhoef M, Barf HA, Post MWM, van Asbeck FWA, Gooskens RHJM, Prevo AJH. Functional independence among young adults with spina bifida, in relation to hydrocephalus and level of lesion. Dev Med Child Neurol. 2006; 48: 114-119.

[11] Hetherington R, Dennis M, Barnes M, Drake J, Gentili F. Functional outcome in young adults with spina bifida and hydrocephalus. Child's Nerv Syst. 2006; 22: 117-124.

[12] Oakeshott P, Hunt GM, Poulton A, Reid F. Expectation of life and unexpected death in open spina bifida: A 40-year complete, non-selective, longitudinal cohort study. Dev Med Child Neurol. 2010; 52: 749-753.

[13] Davis BE Walker WO, Seidel KD, Duguay S. SDB. Acquisition of autonomy skills in adolescents with myelomeningocele. Dev Med Child Neurol. 2006; 48: 253-258.

[14] Thibadeau JK, Alriksson-Schmidt AI, Zabel TA. The national spina bifida program transition initiative: The people, the plan, and the process. Pediatr Clin North Am. 2010; 57: 903-910.

[15] Lindsay S, Mcpherson AC, Maxwell J, Lindsay S, Mcpherson AC, Perspectives JM. Perspectives of school-work transitions among youth with spina bifida, their parents and health care providers. 2017; 39(7): 642-651.

[16] Tapia CI, Khalaf K, Berenson K, Globe D, Chancellor M, Carr LK. Health-related quality of life and economic impact of urinary incontinence due to detrusor overactivity associated with a neurologic condition: A systematic review. Health Qual Life Outcomes. 2013; 11(1): 2-15. 
[17] Sawin K, Bellin M, Roux G, Buran C, Brei T. The experience of self-management in adolescent women with spina bifida. Rehabil Nurs. 2009; 34(1): 26-38.

[18] Schechter MS, Liu T, Soe M, Swanson M, Ward E. Sociodemographic Attributes and Spina Bifida Outcomes. 2015; 135(4): e957-64.

[19] Brei TJ. The future of the multidisciplinary clinic. Scientific World Journal. 2007; 7: 1752-1756.

[20] Dicianno BE, Gaines A, Collins DM, Lee S. Mobility, assistive technology use, and social integration among adults with spina bifida. Am J Phys Med Rehabil. 2009; 88: 533-541.

[21] Bellin MH, Dosa N, Zabel TA, Aparicio E, Dicianno BE, Osteen P. Self-management, satisfaction with family functioning, and the course of psychological symptoms in emerging adults with spina bifida. J Pediatr Psychol. 2013; 38: 50-62.

[22] Mahmood D, Dicianno B, Bellin M. Self-management, preventable conditions and assessment of care among young adults with myelomeningocele. Child Care Health Dev. 2011; 37: 861-865

[23] Wiener JS, Suson KD, Castillo J, Routh JC, Tanaka S, Liu T, et al. Bowel management and continence in adults with spina bifida: Results from the national spina bifida patient registry 2009-15. J Pediatr Rehabil Med. 2017; 10: 335-343.

[24] Cooper J, Chisolm D, McLeod DJ. Sociodemographic characteristics, health literacy, and care compliance in families with spina bifida. Glob Pediatr Heal. 2017; 4: 1-7.

[25] Sawin KJ, Buran CF, Brei TJ, Fastenau PS. Correlates of functional status, self-management, and developmental competence outcomes in adolescents with spina bifida. SCI Nurs 2003; 20: 72-85.

[26] Castillo J, Ostermaier KK, Fremion E, Collier T, Zhu H, Huang GO, et al. Urologic self-management through intermittent self-catheterization among individuals with spina bifida: A journey to self-efficacy and autonomy. J Pediatr Rehabil Med. 2017; 10: 219-226.

[27] Yun HJ, Kim HS. Self-management behaviors of children with spina bifida. J Neurosci Nurs. 2016; 49: 15-21.

[28] King G, Shultz I, Steel K, Gilpin M, Cathers T. Selfevaluation and self-concept of adolescents with physical disabilities. Am J Occup Ther. 1993; 47: 132-140.

[29] Coakley RM, Holmbeck GN, Friedman D, Greenley RN, Thill AW. A longitudinal study of pubertal timing, parentchild conflict, and cohesion in families of young adolescents with spina bifida. J Pediatr Psychol. 2002; 27: 461-473.

[30] White PH, Cooley WC. transitions clinical report authoring group, american academy of pediatrics, american academy of family physicians, american college of physicians. Supporting the Health Care Transition From Adolescence to Adulthood in the Medical Home. Pediatrics. 2018; 142: e20182587.

[31] Health NA to AA. Got Transition [Internet]. 2014 [cited 2019 May 22]. Available from: http://www.gottransition.org/ providers/index.cfm.

[32] Spina Bifida Association [Internet]. Spina Bifida Association. 2019. Available from: https://www.spinabifidaassociation. org/.

[33] Liptak GS, Garver K, Dosa NP. Spina bifida grown up. J Dev Behav Pediatr. 2013; 34: 206-215

[34] Dicianno BE, Wilson R. Hospitalizations of adults with spina bifida and congenital spinal cord anomalies. Arch Phys Med Rehabil. 2010; 91: 529-535.

[35] Sawin KJ, Heffelfinger A, Cashin SE, Brei TJ. The development of the adolescent/Young adult self-management and independence scale II: Psychometric data. J Pediatr Rehabil Med. 2018; 11: 311-322.
[36] Wood DL, Sawicki GS, Miller MD, Smotherman C, LukensBull K, Livingood WC, et al. The transition readiness assessment questionnaire (TRAQ): Its factor structure, reliability, and validity. Acad Pediatr. 2014; 14: 415-422.

[37] Beal SJ, Riddle IK, Kichler JC, Duncan A, Houchen A, Casnellie $\mathrm{L}$, et al. The associations of chronic condition type and individual characteristics with transition readiness. Acad Pediatr. 2016; 16: 660-667

[38] Holbein CE, Murray CB, Psihogios AM, Wasserman RM, Essner BS, O'Hara LK, et al. A camp-based psychosocialiIntervention to promote independence and social function in individuals with spina bifida: Moderators of treatment effectiveness. J Pediatr Psychol. 2013; 38(4): 412-424.

[39] Brewer K, Pollock N, Wright FV. Addressing the challenges of collaborative goal setting with children and their families. Phys Occup Ther Pediatr. 2014; 34: 138-152.

[40] Stubberud J, Langenbahn D, Levine B, Stanghelle J. Goal management training of executive functions in patients with spina bifida: A randomized controlled trial. J Int Neurospsychological Soc. 2013; 19: 672-685.

[41] Kulesz PA, Treble-Barna A, Williams VJ, Juranek J, Cirino PT, Dennis M, et al. Attention in spina bifida myelomeningocele: Relations with brain volume and integrity. NeuroImage Clin. 2015; 8: 72-78.

[42] Zabel TA, Jacobson LA, Zachik C, Levey E, Kinsman S, Mahone EM. Parent- and self-ratings of executive functions in adolescents and young adults with spina bifida. Clin Neuropsychol. 2011; 25(6): 926-941.

[43] Ryan P, Sawin KJ. The individual and family selfmanagement theory: Background and perspectives on context, process, and outcomes. Nurs Outlook. 2009; 57(4): $217-$ $225 \mathrm{e} 6$.

[44] Zukerman JM, Devine K, Holmbeck GN. Adolescent predictors of emerging adulthood milestones in youth with spina bifida. J Pediatr Psychol. 2011; 36: 265-276.

[45] Binks J, Barden WS, Burke T, Young NL. What do we really know about the transition to adult-centered health care? A Focus on Cerebral Palsy and Spina Bifida. Arch Phys Med Rehabil. 2007; 88(8): 1064-1073.

[46] Young NL, Anselmo L, Burke T, McCormick A, Mukherjee S. Youth and young adults with spina bifida: Their utilization of physician and hospital services. Arch Phys Med Rehabil. 2014; 95: 466-471.

[47] Kaufman BA, Terbrock A, Winters N, Ito J, Klosterman A, Park TS. Disbanding a multidisciplinary clinic: Effects on the health care of myelomeningocele patients. Pediatr Neurosurg. 1994; 21: 36-44.

[48] Healthy and Ready to Work Transition Models Project Summary of Effective Approaches. John snow, inc. Boston, MA. 2008.

[49] Betz CL, O'Kane LS, Nehring WM, Lobo ML. Systematic review: Health care transition practice service models. Nurs Outlook. 2016; 64: 229-243.

[50] Berens JC, Peacock C. Implementation of an academic adult primary care clinic for adolescents and young adults with complex, chronic childhood conditions. J Pediatr Rehabil Med. 2015; 8(1): 3-12.

[51] Woodward JF, Swigonski NL, Ciccarelli MR. Assessing the health, functional characteristics, and health needs of youth attending a noncategorical transition support program. J Adolesc Heal. 2012; 51: 272-278.

[52] Rauen KK, Sawin KJ, Bartelt T, Waring WP, Orr M, O'Connor RC. Transitioning adolescents and young adults 
with a chronic health condition to adult healthcare - an exemplar program. Rehabil Nurs. 2013; 38: 63-72.

[53] Lindsay S, Cruickshank H, McPherson A, Maxwell J. Implementation of an interagency transition model for youth with spina bifida. Child Care Health Dev. 2015; 42: 203-212.

[54] West C, Brodie L, Dicker J, Steinbeck K, West C, Brodie L, et al. Development of health support services for adults with spina bifida development of health support services for adults with spina bifida. Disabil Rehabil. 2011; 33: 2381-2388.

[55] Le JT, Mukherjee S. Transition to adult care for patients with spina bifida. Phys Med Rehabil Clin N Am. 2015; 26: 29-38.

[56] Fremion E, Morrison-Jacobus M, Castillo J, Castillo H, Ostermaier K. A chronic care model for spina bifida transition. J Pediatr Rehabil Med. 2017; 10(3-4): 243-247.

[57] Grimsby GM, Burgess R, Culver S, Schlomer BJ. Barriers to transition in young adults with neurogenic bladder. J Pediatr Urol. 2016; 12: 258e1-258.e5.

[58] Summers SJ, Elliott S, McAdams S, Oottamasathien S, Brant
WO, Presson AP, et al. Urologic problems in spina bifida patients transitioning to adult care. Urology. 2014; 84: 440-444.

[59] Shepard C, Doerge E, Eickmeyer A, Kraft K, Wan J, Stoffel JT. Change in care from childhood to adulthood. J Urol. 2018; 199: 1050-1055

[60] Timberlake MD, Corbett ST, Costabile RA, Herndon CDA. Identification of adolescent and adult patients receiving pediatric urologic care and establishment of a dedicated transition clinic. J Pediatr Urol. 2015; 11: 62e1-62e6.

[61] Lindsay S, Hartman LR, Fellin M, Lindsay S, Hartman LR, Fellin M. A systematic review of mentorship programs to facilitate transition to post-secondary education and employment for youth and young adults with disabilities. Disabil Rehabil. 2016; 38: 1329-1349.

[62] Kelly M, Thibadeau J, Struwe S, Ramen L, Ouyang L, Routh JC. Evaluation of spina bifida transitional care practices in the united states. J Pediatr Rehabil Med. 2017; 10: 275-281. 